Energy Research Journal 2 (2): 34-37, 2011

ISSN 1949-0151

(C) 2011 Science Publications

\title{
Electrical Properties of Novel Lead Zirconate/Synthetic Rubber Composite Materials
}

\author{
Chareumwut Pansa-Ard, \\ Yanee Pornchaisiriarun and Nuchnapa Tangboriboon \\ Department of Materials Engineering, Faculty of Engineering, \\ Kasetsart University, Bangkok 10900, Thailand
}

\begin{abstract}
Problem statement: Perovskite lead zirconate exhibits in an orthorhombic formation at a temperature below the Curie temperature, $\mathrm{T}_{\mathrm{C}}$. Approach: The orthorhombic is non-centrosymmetric which is capable of spontaneous polarization (electronic, ionic and orientation), depending on their composition and volume fraction. Results: The results from FTIR spectroscopy, XRD patterns, and SEM indicate that the lead zirconate particles are dispersed in Acrylic Rubber (AR72) matrix. At a small amount of lead zirconate particulates present in the AR72 matrix, at nearly $0.3986 \% \mathrm{~V} / \mathrm{V}$ (AR72/PZ_5), the electrical conductivity increases dramatically by two orders of magnitude. Conclusion/Recommendations: Our synthetic Rubber (AR72)/lead Zirconate $\left(\mathrm{PbZrO}_{3}\right)$ composite materials can be successfully used as the candidate materials of soft Electroactive (ER) actuators, sensors, artificial muscles, and smart engineering devices.
\end{abstract}

Key words: Perovskite lead zirconate, composite materials, actuators, smart engineering devices, artificial muscles, curie temperature

\section{INTRODUCTION}

Composite materials are made of a filler (either particles, flakes or fibers) embedded in a matrix made of polymer, metal and ceramic and composed of any material consisting of two or more distinct phases. Combining a ferroelectric ceramic and a polymer host to form a flexible ferroelectric composite has been pursued in recent years in view of the greater flexibility allowed by these materials to suit particular property requirements such as mechanical, electrical, thermal and/or a coupling between these properties. The characteristics of the ceramic powder depend not only on their composition and their crystal structure but also on the microstructure morphology including grain size, grain boundaries, pores, crystallization, polarization, phase transformation and micro-cracks effect on the properties of composite materials (Dias and DasGupta, 1996).

In our study, we investigate the electrical properties $(\varepsilon$ and $\sigma$ ) of ER solids using lead zirconate particles doped in Acrylic Rubber (AR72) swollen in acetone $\left(\mathrm{CH}_{3} \mathrm{COCH}_{3}\right)$ medium. Acrylic Rubber (AR72) containing polar functional groups tend to be soluble and swollen in polar solvents such as acetone, ethyl acetate, tetrahydrofuran, dichloromethane, acetonetrile, dimethyl formamide and dimethyl sulfoxide. We have also made detailed investigations by SEM, FTIR and XRD to confirm the electrical property results. The electrical properties of both filler and matrix are important in determining applications. Lead Zirconate $\left(\mathrm{PbZrO}_{3}\right)$ and Acrylic Rubber (AR72) composite materials can be used as biomimetic actuators, artificial muscles and smart engineering devices such as active engine mounts, shock absorbers, clutches, brakes, damping devices, hydraulic valves and robotic controlling systems (Dias and Das-Gupta, 1996; Shiga, 1997).

\section{MATERIALS AND METHODS}

Raw material: The production process of pure perovskite lead Zirconate $\left(\mathrm{PbZrO}_{3}\right)$ is successful via the sol-gel process from two precursors as in a previous publication (Tangboriboon et al., 2006; Tangboriboon et al., 2007; Tangboriboon et al., 2008). We used lead glycolate and sodium tris (glycozirconate) as the starting precursors. The obtained molar ratio $(\mathrm{Pb}: \mathrm{Zr})$ of $\mathrm{PbZrO}_{3}$ was 0.9805:1. The structure obtained was in the orthorhombic form when the lead zirconate powder was calcined at $300^{\circ} \mathrm{C}$ for $1 \mathrm{~h}$, which is below the Curie Temperature $\left(\mathrm{T}_{\mathrm{C}}\right)$. The lead zirconate was synthesized

Corresponding Author: Nuchnapa Tangboriboon, Department of Materials Engineering, Faculty of Engineering,

Kasetsart University, Bangkok 10900, Thailand 
and calcined at $300^{\circ} \mathrm{C}$ for $1 \mathrm{~h}$ having the highest dielectrical constant and the highest electrical conductivity of 127.89 and $1.55 \times 10^{-5}(\Omega . \mathrm{m})^{-1}$, respectively, measured at $27^{\circ} \mathrm{C}$ and $50,000 \mathrm{~Hz}$. The specific gravity of calcined lead zirconate powder was $7.50 \mathrm{~g} \mathrm{~cm}^{-3}$. The average particle diameter of the $\mathrm{PbZrO}_{3}$ was approximately $16.724 \pm 0.026$ microns. From the results, the obtained lead zirconate powder has potential applications as materials used in microelectronics, micro-mechanical systems and electro-active ceramics for actuators and smart engineering devices. The Acrylic Rubber (AR72) was supplied by Nippon Zeon Co., Ltd., USA. The AR72 is a fast curing type in a milk-white slab suitable for improving process ability at low compression set, high tensile strength and excellent flow ability of compounds. The Mooney viscosity, $\mathrm{Tg}$ and specific gravity of $\mathrm{AR} 72$ are $33,-28^{\circ} \mathrm{C}$ and $1.11 \mathrm{~g} \mathrm{~cm}^{-3}$, respectively. Acetone (HPLC grade) medium was obtained from Lab-Scan Co., Ltd. The dielectric constant and density of acetone are 21 and $0.786 \mathrm{~g}$ $\mathrm{cm}^{-3}$, respectively.

Sample preparation: Acrylic Rubber (AR72) samples, consisting of polar molecules, were dissolved and swollen in the acetone medium at $20 \%$ by volume. The suspensions were homogeneously mixed by using a magnetic stirrer at room temperature for $24 \mathrm{~h}$. The suspensions were then poured into glass molds like a thin disc $(2-3 \mathrm{~mm})$ to prevent phase separation and covered with glass plates to avoid dust and bubbles and allowed to dry slowly at room temperature overnight.

\section{RESULTS AND DISCUSSION}

Characterization of Acrylic Rubber (AR72)/lead zirconate $\left(\mathrm{PbZrO}_{3}\right)$ composite materials: The FTIR spectra of lead Zirconate $\left(\mathrm{PbZrO}_{3}\right)$, Acrylic Rubber (AR72) and AR72/ $\mathrm{PbZrO}_{3}$ composite materials are shown in Fig. 1. The characteristic peaks of AR72/PbZrO 3 were at: $3400 \mathrm{~cm}^{-1} v(\mathrm{O}-\mathrm{H}) ; 2980 \mathrm{~cm}^{-1}$ $v(\mathrm{C}-\mathrm{H})$ and $v\left(\mathrm{CH}_{2}\right) ; 1727$ and $1790 \mathrm{~cm}^{-1} v(\mathrm{C}=\mathrm{O})$ and $v(\mathrm{C}=\mathrm{C}) ; 1378 \mathrm{~cm}^{-1}\left(\mathrm{CH}_{3}\right.$ asymmetric deformation $)$; $1253 \mathrm{~cm}^{-1} \mathrm{v}(\mathrm{C}-\mathrm{O}-\mathrm{C}) ; 1156 \mathrm{~cm}^{-1}(\mathrm{R}-\mathrm{CO}-\mathrm{R}) ; 1096$ and $1021 \mathrm{~cm}^{-1} v(\mathrm{Zr}-\mathrm{O}-\mathrm{C}) ; 852 \mathrm{~cm}^{-1}$ (C-O-O-C); $796 \mathrm{~cm}^{-1}$ $(\mathrm{C}-\mathrm{O}-\mathrm{Pb})$ and $650 \mathrm{~cm}^{-1}(\mathrm{~Pb}-\mathrm{O})$. FTIR spectra were consistent with the results obtained by Jha and Bhowmick (1997).

The X-ray characteristic peak of pure acrylic rubber, AR72 is amorphous phase. The XRD patterns of pure lead zirconate powder resemble those recorded at the International Center for Diffraction Data (JCPDS) number 35-739, 77-856 and 75-1607. After doping, AR71/ $\mathrm{PbZrO}_{3}$, the X-ray characteristic peaks are at $2 \theta$ equal to $30.289,30.549,30.337,21.339$ and 54.145 indicating that orthorhombic form resemble those recorded JCPDS numbers 35-739, 77-856 and 75-1607 as shown in Fig. 2.

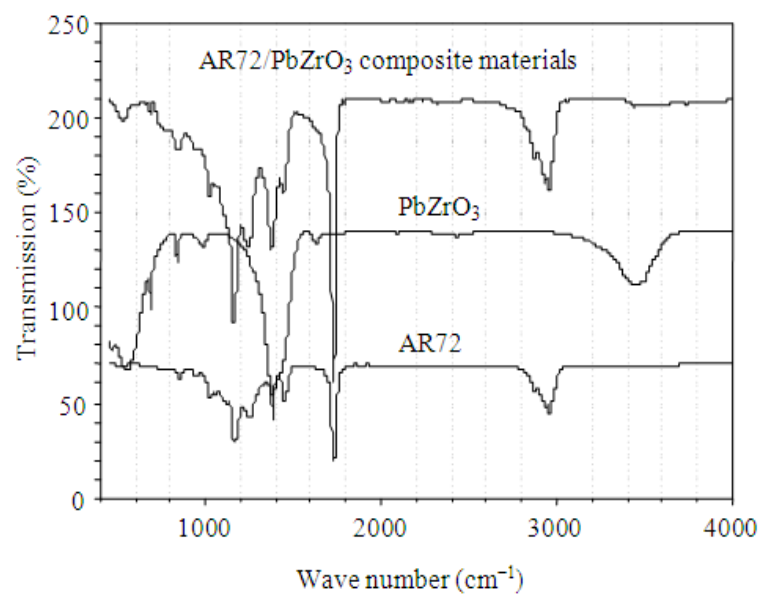

Fig. 1: FTIR spectra of acrylic rubber AR72, lead zirconate $\mathrm{PbZrO}_{3}$ and $\mathrm{AR} 72 / \mathrm{PbZrO}_{3}$ composite materials

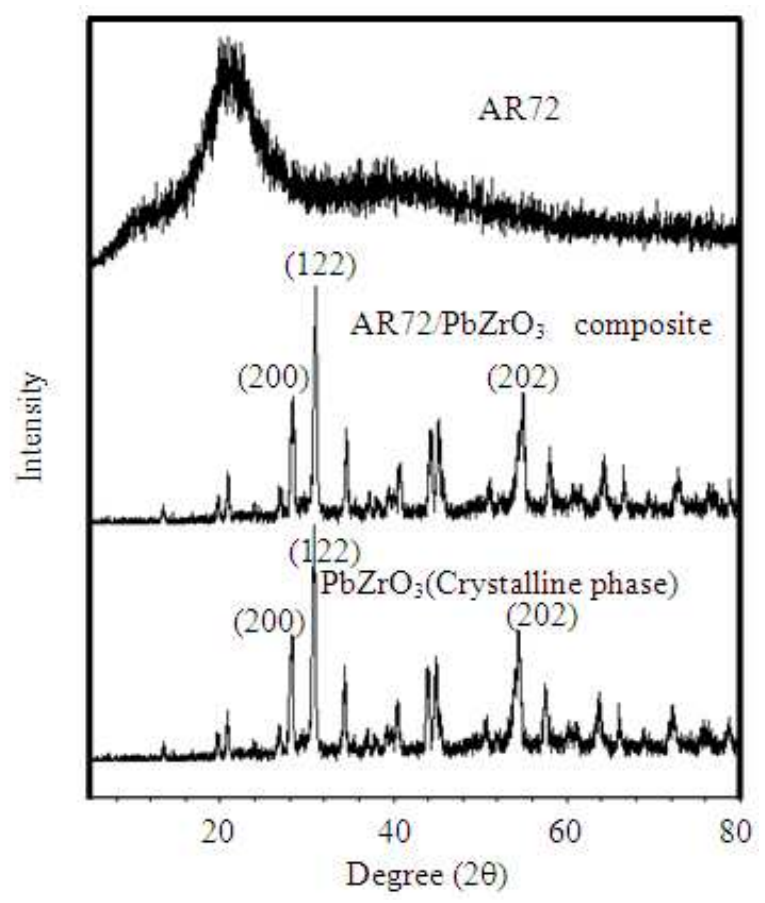

Fig. 2: XRD patterns of acrylic rubber AR72, lead zirconate $\mathrm{PbZrO}_{3}$ and $\mathrm{AR} 72 / \mathrm{PbZrO}_{3}$ composite materials 
Energy Rec. J. 2 (2): 34-37, 2011

Table 1: Electrical properties of $\mathrm{AR} 72 / \mathrm{PbZrO}_{3}$ measured at $27^{\circ} \mathrm{C}$ and at $50 \mathrm{kHz}$ of $2 \mathrm{~A}$ under an $\mathrm{AC}$ electrical field

\begin{tabular}{|c|c|c|c|}
\hline Code & $\mathrm{V} / \mathrm{V}$ of $\mathrm{PbZrO}_{3}(\%)$ & Average dielectric constant at $50 \mathrm{kHz}$ & Average electrical conductivity at $50 \mathrm{kHz}(\Omega . \mathrm{m})^{-1}$ \\
\hline $\mathrm{PbZrO}_{3}$ & 100.0000 & 127.890 & $1.55 \mathrm{E}-05$ \\
\hline AR72/PZ_0 & 0.0000 & 0.718 & $3.20 \mathrm{E}-08$ \\
\hline AR72/PZ_1 & 0.0019 & 0.413 & $3.20 \mathrm{E}-08$ \\
\hline AR72/PZ_2 & 0.0040 & 0.568 & $9.20 \mathrm{E}-08$ \\
\hline AR72/PZ_3 & 0.0200 & 1.154 & $8.00 \mathrm{E}-07$ \\
\hline AR72/PZ_4 & 0.1996 & 1.672 & 3.51E-07 \\
\hline AR72/PZ 5 & 0.3986 & 2.865 & $1.48 \mathrm{E}-06$ \\
\hline AR72/PZ_6 & 1.9646 & 3.590 & 3.43E-06 \\
\hline
\end{tabular}

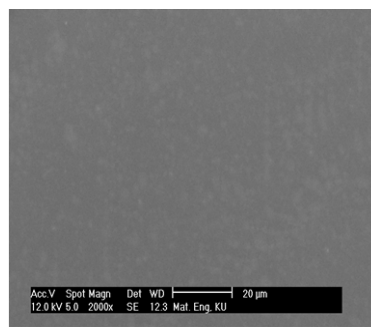

(a)

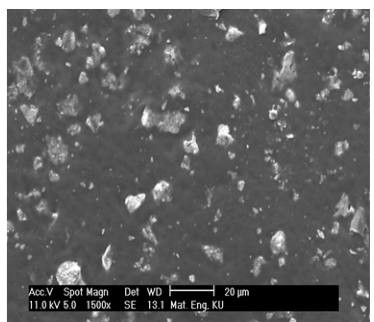

(c)

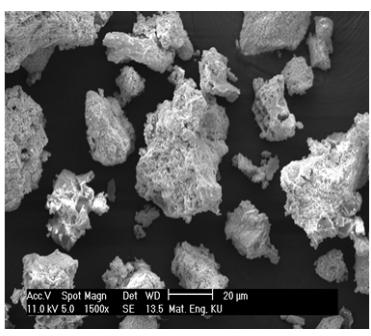

(b)

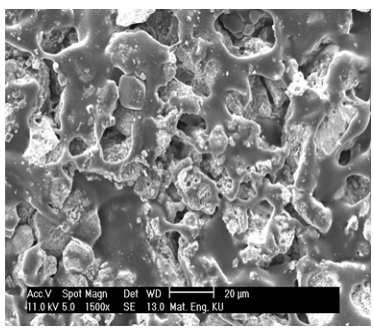

d)
Fig. 3: SEM micrographs of (a) acrylic rubber AR72; (b) lead zirconate $\mathrm{PbZrO}_{3}$; (c) AR72/PZ_5; (d) AR72/PZ_6

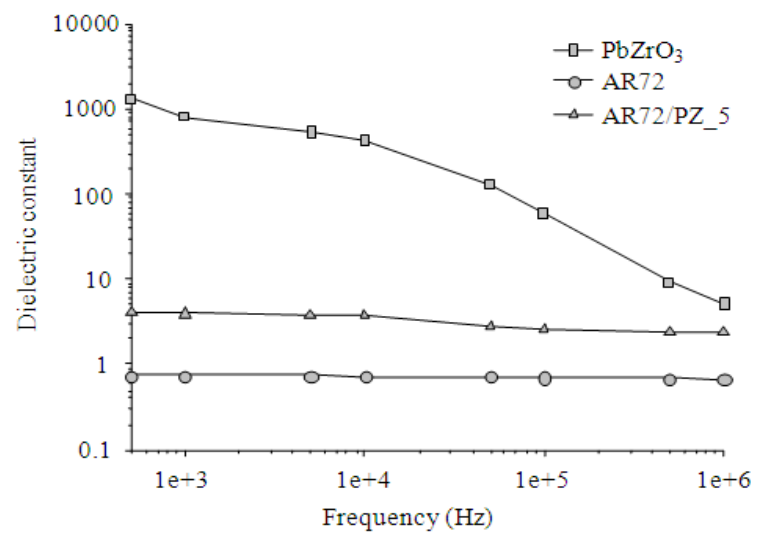

Fig. 4: Dielectric constant Vs frequency of an AC electrical field of acrylic rubber AR72/lead zirconate $\mathrm{PbZrO}_{3}$

The microstructures of pure Acrylic Rubber (AR72), $\mathrm{PbZrO}_{3}, \mathrm{AR} 72 / \mathrm{PZ} \_5$ and AR72/PZ_6 obtained by SEM with a magnification of 1500 and 2000 at $11 \mathrm{kV}$, are shown in Fig. 3a is a micrograph of the Acrylic Rubber (AR72). The average particle diameter of $\mathrm{PbZrO}_{3}$ is approximately $16.724 \pm 0.026$ microns (Tangboriboon et al., 2006; 2007; 2008) as shown in Fig. 3b; it is quite irregular in shape. Figure $3 \mathrm{c}$ shows uniform dispersion of the doped $\mathrm{PbZrO}_{3}$ particles with 0.3986 $\%$ V/V within the AR72 matrix. AR72/PZ_6 sample suggests non-uniform dispersion or agglomeration of lead zirconate particles with high volume fraction 0.019646 in Acrylic Rubber (AR72) as shown in Fig. 3d.

Electrical properties of Acrylic Rubber (AR72)/lead Zirconate $\left(\mathrm{PbZrO}_{3}\right)$ : Effect of concentration: The electrical properties of Acrylic Rubber (AR72), piezoelectric material $\left(\mathrm{PbZrO}_{3}\right)$ and $\mathrm{AR} 72 / \mathrm{PbZrO}_{3}$ were investigated by using an impedance analyzer with an $\mathrm{AC}$ field at $50 \mathrm{kHz}$ as the data are tabulated in Table 1. With the increase of particulate volume fraction, the electrical conductivity and dielectric constant increase gradually. The dielectric constant values are 0.718 , 127.89 and 3.590 for $\mathrm{AR}^{2}, \mathrm{PbZrO}_{3}$ and AR72/PZ_6, respectively.

The electrical conductivities of $\mathrm{AR72}, \mathrm{PbZrO}_{3}$ and AR72/PZ_6 are $3.20 \times 10^{-8}, 1.55 \times 10^{-5}$ and $3.43 \times 10^{-6}(\Omega . \mathrm{m})^{-1}$, respectively. The electrical conductivity of AR72/PZ_6 is larger than two orders of magnitude observed in acrylic rubber AR72. The acrylic rubber can be swollen by acetone. The lead zirconate particles were intercalated in the acrylic rubber, AR72 matrix. The inductive effect of the dielectric materials induced polarization by the imposition of external forces applied by an AC electrical field:

$$
\text { Density of AR72 }=1.11 \mathrm{~g} \mathrm{~cm}^{-3}
$$

$$
\text { Density of } \mathrm{PbZrO}_{3} \text { powder }=7.50 \mathrm{~g} \mathrm{~cm}^{-3}
$$

Effect of field frequency: Figure 4 shows variation of dielectric constant and electrical conductivity with a frequency of an alternating electrical field of AR72, $\mathrm{PbZrO}_{3}$ and AR72/PZ_5. The dielectric constant and 
electrical conductivity of samples were measured two or three times at $27^{\circ} \mathrm{C}$ and at $50 \mathrm{kHz}$. Acrylic rubber (AR72)/lead zirconate $\left(\mathrm{PbZrO}_{3}\right)$, AR72/PZ_5, exhibits enhancing dielectric constant applied by electrical field because of electronic, ionic and orientation polarizations. The best sample is AR72/PZ_5.

\section{CONCLUSION}

Our results suggest that dielectric lead zirconate $\left(\mathrm{PbZrO}_{3}\right)$ particles can be used as a filler, to improve electrical properties within the acrylic rubber matrix. The perovskite phase and orthorhombic formation of synthesized lead Zirconate $\left(\mathrm{PbZrO}_{3}\right)$ at below $\mathrm{T}_{\mathrm{C}}$ exhibits ferroelectric behavior to show spontaneous polarization (electronic; ionic; orientation) in the position of $\mathrm{Pb}^{2+}, \mathrm{Zr}^{4+}$ and $\mathrm{O}^{2-}$ ions as well as possess the non-centrosymmetric structure such as tetragonal and rhombohedral forms (Callister and Rethwisch, 2010). The electrical properties-dielectric constant and electrical conductivity of the best sample, AR72/PZ_5, at a small volume fraction of $\mathrm{PbZrO}_{3}(0.003986)$ are 2.865 and $1.48 \times 10^{-6}(\Omega . \mathrm{m})^{-1}$, respectively. Both SEM and electrical property results showed that AR72/PZ_5 could be a composite material for biomimetic actuators, artificial muscles, vibration isolators and smart engineering devices.

\section{ACKNOWLEDGEMENT}

The researcher would like to thank the Faculty of Engineering, Kasetsart University (Thailand) for their financial support and the Departments of Materials Engineering and Physics, Kasetsart University, for the use of the analytical equipment.

\section{REFERENCES}

Callister, W.D. and D.G. Rethwisch, 2010. Materials Science and Engineering. 8th Edn., Wiley, Hoboken, NJ., ISBN-10: 0470505869, pp: 885.

Dias, C.J. and D.K. Das-Gupta, 1996. Inorganic ceramic/polymer ferroelectric composite electrets. IEEE Trans. Dielect. Elect. Insulat., 3: 706-734. DOI: $10.1109 / 94.544188$

Jha, A. and A.K. Bhowmick, 1997. Thermoplastic elastomeric blends of poly(ethylene terephthalate) and acrylate rubber: 1 . Influence of interaction on thermal, dynamic mechanical and tensile properties. Polymer, 38: 4337-4344. DOI: 10.1016/S0032-3861(96)01028-2

Shiga, T., 1997. Deformation and viscoelastic behavior of polymer gels in electric fields. Adv. Polymer Sci., 134: 131-163. DOI: 10.1007/3-540-684492_2

Tangboriboon, N., A. Jamieson, A. Sirivat and S. Wongkasemjit, 2008. A novel route to perovskite lead zirconate titanate from glycolate precursors via the sol-gel process. Applied Org. Chem., 22: 104-113. DOI: 10.1002/aoc.1357

Tangboriboon, N., K. Pakdeewanishshsukho, A. Jamieson, A. Sirivat and S. Wogkasemjit, 2006. Electrical properties of a novel lead alkoxide precursor: Lead Glycolate. Mater. Chem. Phys., 98: 138-143. 10.1016/j.matchemphys.2005.09.034

Tangboriboon, N., A. Jamieson, A. Sirivat and S. Wogkasemjit, 2007. A novel route to perovskite lead zirconate from lead glycolate and sodium tris(glycozirconate) via the sol-gel process. Applied Org. Chem., 21: 849-857. DOI: 10.1002/aoc. 1303 